\title{
Comparative Study of 2 Doses of Sufentanyl (2.5 Mg versus 5 Mg) in the Rachianesthsia for Cesarean Section
}

\author{
Ango Privat Desire ${ }^{1 *}$, Kone Nabitou ${ }^{2}$, Adje Tchimou Serge ${ }^{3}$, Kouame Kouadio Antoine ${ }^{4}$, Sai \\ Servais Sontia ${ }^{4}$, Diomande Sogbety Erick ${ }^{5}$, Boua Narcisse ${ }^{6}$ \\ ${ }^{1}$ Clinic Manager's Assistant at Felix Houpouet Boigny University in Abidjan; Abidjan Medical Sciences \\ Training and Research Unit (UFR-SMA) 17 BP 71 Abidjan 17 - Republic of Côte d'Ivoire (RCI) \\ ${ }^{2}$ Anesthetist, Clinic Manager's Assistant; UFR -SMA \\ ${ }^{3}$ Anesthetist, Hospital Assistant; Hospital University (HU) of Treichville, Republic of Côte d'Ivoire \\ ${ }^{4}$ Internal Hospital; Hospital University (HU) of Treichville, Republic of Côte d'Ivoire \\ ${ }^{5}$ Hospital interns, Hospital University (HU) of Treichville, Republic of Côte d'Tvoire \\ ${ }^{6}$ Anesthetist, University Professor, Alasane ouattara Unversity in Bouaké. Bouaké Medical Sciences Training \\ and Research Unit (UFR -SM Bouaké), Republic of Côte d'Ivoire
}

*Corresponding Author: Ango Privat Desire, Clinic Manager's Assistant at Felix Houpouet Boigny University in Abidjan; Abidjan Medical Sciences Training and Research Unit (UFR-SMA) 17 BP 71 Abidjan 17 - Republic of Côte d'Ivoire (RCI), Email: privatango@yahoo.fr

\begin{abstract}
Background: During the Rachianesthesia, many substances including opioids, are administered intrathecally as adjuvants of local anesthetics. The aims, was to compare the efficacy of spinal anesthesia with bupivacaine $10 \mathrm{mg}$ plus sufentanyl 2,5 versus 5 micrograms during caesarean section.

Methods: This is a descriptive, comparative and retrospective study conducted in the operating room of the obstetrics and gynecology department of the University Hospital of Treichville from April 2017 to March 2018. Were included in the study, 80 patients classified ASA I and II who underwent spinal anesthesia for cesarean section either with the combination of bupivacaine $10 \mathrm{mg}+$ sufentanyl $2.5 \mathrm{~g}$ (Group I, $n=37$ ) or Bupivacaine $10 \mathrm{mg}+$ sufentanyl $5 \mu \mathrm{g}$ (Group II, $n=43$ ). Our primary evaluation criteria were: duration of sensory and motor block, ephedrine consumption, and incidence of side effects peropeatively. Comparisons were made using the Chi 2 test, with a threshold of $p \leq 0.05$ considered significant.

Results: The criteria evaluated in our patients studied were comparable: age $(p=0.315)$, size $(p=0.43)$, duration of motor block $(p=0.616)$, duration of postoperative analgesia $(p=0.30)$, as well as pruritus $(p=$ 0.69). The incidence of side effects such as: Hypotension $(p=0.00)$, somnolence $(p=0.000)$, nausea $(p=$ $0.00)$ vomiting $(p=0.04)$, were higher in Group II than in Group I. The distribution of patients according to the consumption of ephedrine was: $0.32 \pm 1.97$ (Gr I) vs $16.14 \pm 7.29$ (Gr II), with a significant stastiscal difference $(p=0.000)$
\end{abstract}

Conclusions: Spinal anesthesia with bupivacaine $10 \mathrm{mg}$ and sufentanyl $2.5 \mathrm{mcg}$ provides satisfactory operating conditions and reduction of side effects compared to sufentanyl $5 \mu \mathrm{g}$.

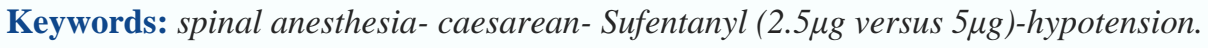

\section{INTRODUCTION}

Spinal anesthesia since its discovery in the nineteenth century until today has seen many variations and practical changes in order to ensure the patients quality anesthesia with less side effects. It is a simple, fast and reliable technique that offers a spinal block of excellent quality; it remains the method of choice for cesarean section, unless in case of documented contra-indications $[1,2,3,4]$.
In this dynamic, many substances, including morphine, are associated intrathecally to local anesthetics during spinal anesthesia [4]. They can thus reduce the dosage and the hemodynamic effects of local anesthetics, prolong the action time of the spinal block and finally obtain intense and prolonged postoperative analgesia.

In contrast, significant side effects such as arterial hypotension and respiratory depression 
have been reported according to the type and dosage of morphine used $[5,6,7,8,9,10,11]$.

Sufentanyl has been used in intrathecal injection for many years by teams $[8,10,12]$. The availability of sufentanyl in our hospital since January 2017 motivated our work.

The purpose of this study was to compare the clinical effects of two (2) doses of sufentanyl used as intrathecal bupivacaine adjuvants for caesarean section.

\section{METHODS}

For this study, the pre anesthetic consultation was systematic during the last trimester of pregnancy (between the $8^{\text {th }}$ and $9^{\text {th }}$ months of pregnancy). It was conducted in the operating room of gynecology and obstetrics department of the CHU (University Hospital) of Treichville. It was a retrospective, descriptive and comparative study over a period of twelve (12) months (April 2017 to March 2018).

Were included in the study patients whose Caesarean was planned or carried out as part of emergency under Spinal anesthesia. They have been classified as ASA 1 or 2 .

Were excluded from our study, patients presenting blood-stasis disorders, underlying severe maternal and fetal pathologies (Placenta bleeding previa, uterine rupture, pre rupture syndrome, eclampsia and pre-eclampsia), patients benefiting from general anesthesia for caesarean section.

Eighty (80) patients were randomised according to the order of interventions in two Groups $(\mathrm{Gr})$ : I $(n=37)$ and II $(n=43)$ respectively with a dose $2.5 \mu \mathrm{g}$ and $5 \mu \mathrm{g}$ of sufentanyl as an adjuvant to bupivacaine $10 \mathrm{mg}$ intrathecally. The mixtures were prepared at the time of use.

All parturients of our study were placed in a seated position asking them to round their backs.

Puncture under strict asepsis was performed in the vertebral space L3- L4 by median route or para median sometimes with a short bevel needle 26- 27 Gauge. This needle was laterally inserted in search of subarachnoid space using an introducer also inserted after local anesthesia, laterally under the skin.

Parturients were placed in supine position after spinal anesthesia with elevation of the right buttock.

The time intervals were measured after intrathecal injection of the anesthetic solution.
Per operatively, 6 to $9 \mathrm{mg}$ boluses of ephedrine were injected according to maternal arterial hypotension: SBP (Systolic Blood Pression <90 $\mathrm{mmHg}$ or $20 \%$ decrease from baseline value), DBP (Diastolic Blood Pression $<45 \mathrm{mmHg}$ ) or ABP (Average Blood Pression $<65 \mathrm{mmHg}$ ).

The analgesic level was tested by cold sensation (T). While the level of the motor block was appreciated by the score of Bromage modified $(0=$ no paralysis, $1=$ only able to move the knee, 2 = only able to move the feet, $3=$ incapacity to move the leg or the knee).

An analgesic test by the pinching of the integuments by a Kocher forceps at the first notch allows the incision of the skin on the order of the anesthetist doctor.

Automatic measurements of hemodynamic constants (SBP, DBP, ABP, and Heart Rate (HR)) for the surveillance of the parturient are performed every $5 \mathrm{~min}$. until the end of the skin closure. The following parameters were measured and recorded on a listing of individual survey:

In preoperative: Age, height, Caesarean section indication, SBP, DBP, ABP, HR and ASA class.

In per and postoperative: Heart Rate (HR), the consumption of ephedrine, the incidence of side effects (maternal hypotension, dizziness, drowsiness, nausea /vomiting, headache, pruritus) and the duration of the motor and sensory block.

The collection of data was made from the anesthetic and individual survey card.

Production of tables using Statiscal software Package for Social Sciences version 8. The results are expressed in mean values \pm standard derivation (SD).

Statistical comparisons were made in a bilateral situation, with a risk of error of first degree of $5 \%$ with the Student's test $(\mathrm{t})$ for digital values, and a Chi-2 test for non-digital values. A value of $p<0.05$ is considered as significant.

\section{RESUlTS}

During the study period, 80 Patients were collected for the study, including 37 cases for the Group I. The average age was $30.43 \pm 4.54$ years for Group I and $30.88 \pm 5.05$ years for Group II $(p=0.3153)$. The average size was $163.81 \pm 5.19 \mathrm{~cm}$ for Group I and $166.19 \pm 4.56$ cm for Group II ( $p=0.43$ ) (Table 1). 
Comparative Study of 2 Doses of Sufentanyl (2.5 Mg versus $5 \mathrm{Mg}$ ) in the Rachianesthsia for Cesarean Section

Table1: Distribution of patients according to different data

\begin{tabular}{|l|l|l|l|l|}
\hline & Gr I & Gr II & Ki 2 & $p$ \\
\hline epidemiological & & & & \\
Ages (year) & $30.43 \pm 4.54$ & $30.88 \pm 5.05$ & - & 0.3153 \\
Height(cm) & $163.81 \pm 5.19$ & $166.19 \pm 4.56$ & 0.61 & 0.43 \\
ASA 1 & 48.6 & 32.6 & 2.12 & 0.14 \\
$\quad 2$ & 51.4 & 67.4 & & \\
\hline Anesthetic & & $46.81 \pm 5.67$ & 7.04 & 0.07 \\
Duration of the intervention (min) & $52.14 \pm 15.84$ & $212.93 \pm 37.89$ & 3.63 & 0.30 \\
Duration of analgesia (min) & $198.38 \pm 57.69$ & $2.32 \mathrm{~h} \pm 32.237$ & 1.79 & 0.616 \\
Duration of the motor block (h) & $2.54 \mathrm{~h} \pm 38.14$ & & \\
\hline
\end{tabular}

cm: centimeter min: minutes; : hour; $p>0.05=$ The difference between these two groups is not significant; Gr $I=$ Group I; Gr II = Group II

The cesarean indications $\left(\mathrm{X}^{2}=6.21 p=0.1838\right)$ were dominated in our series by acute fetal distress $(39.5 \%$ for the Group II and $27 \%$ for the Group I), and scar uterus $(25,6 \%$ for Group II and $32.5 \%$ for Group I). They were followed by pelvic fetal disproportions (Gr I : $16.2 \%$; Gr Table2: Repartition of patients by cesarean indications
II : $16.3 \%$ ), stationary dilatation (Gr I: $13.5 \%$; Gr II: $18.6 \%$ ), and dystocic presentations (Gr I: $10.8 \%$; Gr II : 0\%) Table 2. The level of cephalic extension reached was comparable in the two groups $\mathrm{X}^{2}=6.39 p=0.094$ (Table 3).

\begin{tabular}{|l|l|l|}
\hline & Group I n(\%) & Group II n(\%) \\
\hline FPD & $6(16.2)$ & $7(16.3)$ \\
\hline Stationary dilatation & $5(13.5)$ & $8(18.6)$ \\
\hline Dystocic presentation & $4(10.8)$ & $0(0.0)$ \\
\hline Acute Fetal Suffering (AFS) & $10(27)$ & $17(39.5)$ \\
\hline Scar uterus & $12(32.5)$ & $11(25.6)$ \\
\hline
\end{tabular}

$X^{2}=6.2125 ; p=0.1838 ; F P D=$ Foeto Pelvic Disproportion

Table3: Distribution of patients according to sensory level reached

\begin{tabular}{|l|l|l|}
\hline & Group I n(\%) & Group II n(\%) \\
\hline Mamelon (T4) & $10(27.03)$ & $7(16.28)$ \\
\hline Umbilicus (T10) & $1(2.70)$ & $4(9,30)$ \\
\hline xyphoid appendix (T6) & $2(5.41)$ & $9(20.93)$ \\
\hline Between the xyphoid appendix and the umbilicus (T8) & $24(64.86)$ & $23(53.49)$ \\
\hline
\end{tabular}

$\%$ : percentage $n$ : population $; X^{2}=6.39 p=0.094$ (non significant difference)

The average duration of interventions was 52.14 $\pm 15.84 \mathrm{~min}$ for $\mathrm{Gr} \mathrm{I}$ and $46.81 \pm 5.67 \mathrm{mins}$ for Gr II $(p=0.07)$ (Table I). The average duration of analgesic block was respectively of $198.38 \pm$ 57.69 and $212.93 \pm 37.89 \mathrm{~min}$ for Gr I and II ( $p$ $=0.30)$. The average duration of motor block was $2.54 \mathrm{~h} \pm 38.141 \mathrm{~min}$ for $\mathrm{Gr} \mathrm{I}$ and $2.32 \mathrm{H} \pm$ $32.237 \mathrm{~min}$ for Gr II ( $p=0.616)$ (Table I). The distribution of patients according to the average consumption of ephedrine was respectively 0.32 \pm 1.97 and $16.14 \pm 7.29$ for Gr I and II $(p=$ 0.000) Table V. In group I, only one patient received $12 \mathrm{mg}$ of ephedrine, while in the other Gr 7, 15 and 16 patients received respectively

Table4: Distribution of patients according side effects observed

\begin{tabular}{|l|l|l|l|}
\hline & Group I n(\%) & Group II n(\%) & $p$ \\
\hline Headaches & $0(0)$ & $5(11,63)$ & $0.03 *$ \\
\hline Dizziness & $1(2.70)$ & $7(16,28)$ & $0.04 *$ \\
\hline Drowsiness & $2(5.40)$ & $22(51,16)$ & $0,00 *$ \\
\hline
\end{tabular}

$30 \mathrm{mg}, 12 \mathrm{mg}$ and $15 \mathrm{mg}$ of ephedrine during the caesarean section.

The incidence of side effects was higher in the $\mathrm{Gr}$ II versus Gr I (Table 4). No respiratory depression was observed in both groups (Table 4).

Newborn Apgar was satisfactory, the difference between the two groups was statistically insignificant $\left(\mathrm{X}^{2}=5.53 ; p=0.062\right)$

The distribution of patients according to the consumption of ephedrine was: $0.32 \pm 1.97$ ( $\mathrm{Gr}$ I) vs $16.14 \pm 7.29$ (Gr II), with a significant stastiscal difference $(p=0.000)$ Table 5 
Comparative Study of 2 Doses of Sufentanyl (2.5 Mg versus $5 \mathrm{Mg}$ ) in the Rachianesthsia for Cesarean Section

\begin{tabular}{|l|l|l|l|l|}
\hline Nausea & $1(4.70)$ & 2967.44 & $0,00 *$ \\
\hline Vomiting & $1(2.70)$ & 16.28 & $0.04 *$ \\
\hline Hypotension & $3(8.82)$ & 3376.74 & $0,00 *$ \\
\hline Pruritus & $13(35.13)$ & 1739.53 & $0.69(\mathrm{NS})$ \\
\hline Discomfort & $0(0)$ & 2046.51 & $0,00 *$ \\
\hline
\end{tabular}

$\%:$ percentage; $n:$ population; $N S=$ non significant difference; $p=$ probability; $*$ significant difference

Table5: Distribution of patients according to ephedrine doses ( $\mathrm{mg}$ )

\begin{tabular}{|l|l|l|}
\hline & Group I n(\%) & Group II n(\%) \\
\hline Dose (mg) & & \\
\hline 0 & $36(97.3)$ & $2(4.7)$ \\
\hline 12 & $1(2.7)$ & $15(34.9)$ \\
\hline 15 & $0(0.0)$ & $16(37.2)$ \\
\hline 20 & $0(0.0)$ & $2(4.7)$ \\
\hline 24 & $0(0.0)$ & $1(2.3)$ \\
\hline 30 & 0.00 & $7(16.3)$ \\
\hline
\end{tabular}

Average: $G r I=0.32 \pm 1.97 ; G r I I=16.14 \pm 7.29 ; \quad X^{2}=59.77 p=0.000$

\section{DISCUSSION}

This study showed that both doses of sufentanyl had no significant influence on the cephalic extension, on the duration of analgesic and motor blocks in both groups. On the other hand, the side effects reported during spinal anesthesia were greater with the dose of $5 \mu \mathrm{g}$ than that of $2.5 \mu \mathrm{g}$.

Indeed, the extension of sensory block was similar in all our patients studied ( $p=0.094)$. The upper level of the block, determined by the distribution of the local anesthetic in the cerebrospinal fluid (CSF), before attachment to the roots, depends on the injection technique (puncture level, injection rate, patient position), injected solution (volume) of patient (age, height, weight) $[4,13,14,15]$. The average duration of analgesia in minutes was: $\mathrm{Gr} \mathrm{I}$ : $198.38 \pm 57.70$ and Gr II: $212.93 \pm 37.89$. Values super imposable to ours were found by BEN DAVID (195 $\pm 49 \mathrm{~min})$ [16].

In Côte d'Ivoire MIGNONSIN D. et al., By varying the baricity of isobaric bupivacaine by cooling found an analgesic duration longer $(276.40 \pm 32.23 \mathrm{~min})$ [9]. Similarly JORGEN B et al in a comparative study carried out in Denmark, found in patients treated by isobaric bupivacaine (12.5 $\mathrm{mg})$ - sufentanyl average duration of analgesia of $270 \mathrm{~min} \mathrm{[17].} \mathrm{In}$ general, the addition of sufentanyl to bupivacaine did not change the duration of sensory block nor the cephalic extension of the block in both groups, but the sensory level achieved was sufficient to ensure good condition of intervention in all patients. As for the average duration of motor bloc, it was $2.54 \mathrm{H} \pm 38.141 \mathrm{~min}$ for $\mathrm{Gr} \mathrm{I}$ and $2.32 \mathrm{H} \pm$
$32.237 \mathrm{~min}$ for Gr II. This duration was super imposable to the results found in classical literature which was 3Hours on average for D'ATHIS et al. It is the same with HOUSNI B et al. $[18,19]$. We can say that increasing the dose of sufentanyl as adjuvant to the local anesthetic solution does not influence the duration of the motor block ( $p>0.05$ ).

The distribution of patients according to ephedrine consumption was: $0.32 \pm 1.97$ (Gr I) vs $16.14 \pm 7.29$ (Gr II), with a significant statistical difference proving the synergistic action of opioids associated with local anesthetics. A similar consumption of ephedrine was found in several studies mainly, that of Minif Ma et al $(28 \pm 2)$ [20], Bouchnak et al. $(22.0 \pm 15.0)[21,22]$.

During our study, the hemodynamic variations between the two groups were important. The blood pressure was found in $8.82 \%$ of cases $(\mathrm{Gr}$ I) as against $76.74 \%$ ( $\mathrm{G} r$ II) with such a significant difference $(p=0.000)$. Also the consumption of ephedrine, a vasopressor used in the curative treatment of hypotension, was also important in Gr II. The increase in the sufentanyl dose intrathecally had a marked influence on the hemodynamic profile of the patients. It was a vasoplegia associated with a state of discomfort that was statistically significant $(\mathrm{p}=0.000,46.51 \%)$. Similar results to those of this study $[10,23]$ were found by Trik et al [24] MIGNONSIN D. et al. [9]

In our study, the adverse effects (nausea, vomiting) were more marked in the Gr II ( $\mathrm{p}=$ $0.00, p=0.04)$. Numerous comparative studies have proved that the existence of nausea and vomiting was due to the presence of opioids in 
the anesthetic solution [4, 10, 11, 25, 26, 27]. These side effects achieved by adding colloids in pre-filling were opposed to ours according to Siddik et al [28]. We can say that the pre-filling in this study with colloids had influenced the risk of nausea and vomiting. Similarly BOUCHNAK et al in a similar study, wanting to appreciate the influence of the injection speed of the mixture anesthetic bupivacaine-fentanyl $(10 \mu \mathrm{g})$-morphine base, non significantly noted the presence of nausea and vomiting in their study population $(\mathrm{p}=0.43, \mathrm{p}=0.75)$ [21].

Other side effects related to vasoplegia, namely general discomfort, somnolence, vertigo, were found in significant proportions in the GrII ( $\mathrm{P}=$ $0.000)$. These results are similar to those found in the literature $[21,25,28]$.

This dose, as confirmed by Hunt Co et al. may be reduced to $10 \mu \mathrm{g}$ of fentanyl, that is 1 gamma of sufentanyl, and thus allow the reduction of the side effects of spinal anesthesia, in particular arterial hypotension [29].

\section{CONCLUSiON}

This work has shown that side effects observed in spinal anesthesia were more marked with a dose of $5 \mu \mathrm{g}$ of sufentanyl and lesser with a dose of $2.5 \mu \mathrm{g}$ of sufentanyl. The anesthetic block was of good quality in both groups. This study will advise the dose of $2.5 \mu \mathrm{g}$ sufentanyl as adjuvant for the performance of spinal anesthesia for cesarean section.

\section{REFERENCES}

[1] Dahlgren G. Hultstrand C, Jakobsson J, Norman M, Eriksson EW, Martin H. Intrathecal Sufentanil, Fentanyl, or Placebo Added to Bupivacaine for Cesarean Section. Anesth Analg 1997;85:1288-93

[2] Gueguen G. La Rachianesthésie en Afrique : Risques, Précautions à prendre. Cah Anesthesiol. 1994;42(5):651-6. [PubMed]

[3] Dominique I, Abid N, Badet L, Boselli E. Rachianesthésie en chirurgie ambulatoire urologique: étude rétrospective. Prog Urol. 2015;25(13):790. doi: 10.1016/j.purol.2015.08. 148.

[4] Bonnet F., Marret E. Indications de la rachianesthésie en 2001. Evaluation et traitement de la douleur. Conférences d'actualisation 2001, Éditions scientifiques et médicales Elsevier SAS, et SFAR. 2001: p7-14. Consulted february 2, 2019 http://jpmiss2.free. fr/Divers/SFAR 2008/ dou01/html/d01_01/D01_01.htm.

[5] Bennasr L, Ben Marzouk S, Ajili Z, Riahi A, Jarraya MA, Massoudi S, Jabri H, Maghrebi H.
Prévention de l'hypotension induite par la rachianesthésie au cours de la césarienne programmée : coremplissage par HEA 130/0,4 vs sérum salé isotonique. Ann $\mathrm{Fr}$ Anesth Reanim. 2014;33(12):643-7.http://dx.doi.org/ 10.1016/j.annfar.2014.10.004.

[6] Richard G., Wright MD., Sol M., Shnider M.D. Hypotension and regional anesthesia in obstetrics. In Anesthesia for obstetrics, 2ème édition. WILLIAMS \& WILKINS, 1987, p. 293299.

[7] Ngan Kee WD. Preventing hypotensioninduced nausea and vomiting during spinal anesthesia for Cesarean delivery in obese parturients: a small solution for a big problem? Can J Anaesth. 2018;65(3):235-238. doi: 10. 1007/s12630-017-1035-5.

[8] Vyas N, Sahu DK, Parampill R. Comparative study of intrathecal sufentanil bupivacaine versus intrathecal bupivacaine in patients undergoing elective cesarean section. $J$ Anaesthesiol Clin Pharmacol. 2010;26(4):48892.

[9] Mignonsin D; Kane M.; Bondurand A. Facteurs liés à la durée de l'analgésie au cours de la rachianesthésie. Med. Afr. Noire: 1993, 40(1): 29-32.

[10] Farzi F, Mirmansouri A, Naderi Nabi B, and al. Comparing the Effect of adding Fentanyl, Sufentanil, and Placebo with Intrathecal Bupivacaine on Duration of Analgesia and Complications of Spinal Anesthesia in Patients Undergoing Cesarean Section. Anesth Pain Med. 2017;7(5):e12738. doi: 10.5812/aapm.12 738

[11] Jokinen J, Smith AF, Roewer N, Eberhart LH, Kranke P. Management of postoperative nausea and vomiting: how to deal with refractory PONV. Anesthesiol Clin. 2012; 30(3):481-93. doi: 10.1016/j.anclin.2012.07.003.

[12] Cohen SE, Cherry CM, Holbrook RH Jr, elSayed YY, Gibson RN, Jaffe RA. Intrathecal sufentanil for labor analgesia-sensory changes, side effects, and fetal heart rate changes. Anesth Analg. 1993;77(6):1155-60.

[13] Douglas J., Choid D. Spinal anesthesia for obstetrics: discovery, rediscovery. Can J Anesth. 2000,47(9) : 833-6. doi:10.1007/ BF03019660

[14] Eledjam JJ., Brulle P., Cuvillon P. Contreindications à l'anesthésie rachidienne chez l'adulte. Conférences d'actualisation 1998, Éditions scientifiques et médicales Elsevier SAS, et SFAR 1998, p. 217-234. Consulted february, 28, 2019http://jpmiss2.free. fr/Divers/ SFAR_2006/ca98/html/ca98_17/98_017.htm

[15] Samii Kamran, Gentili M. Rachianesthesie, Pratiques en Anesthesie, en Reanimation, et Urgences. Elsevier Masson. 2003, p.270. 
[16] Ben-David B, Solomon E, Levin H, Admoni H, Goldik Z Intrathecal Fentanyl With SmallDose Dilute Bupivacaine: Better Anesthesia Without Prolonging Recovery Anesth Analg 1997; 85 (3) :560-5.

[17] Dahl JB, Jeppesen IS, Jorgensen H, Wetterslev J, Moiniche S. Intraoperative and Postoperative Analgesic Efficacy and Adverse Effects of Intrathecal Opioids in Patients Undergoing Cesarean Section with Spinal Anesthesia: a qualitative and quantitative systematic review of randomized controlled trials. Anesthesiology. 1999;91(6):1919-27.

[18] D’Athis F. François G., Cara M., Du Caillar J., et al. La rachianesthésie In : Précise d'anesthésie. (1981).p203-9

[19] Housni B, Miguil M. Hypotension artérielle au cours de rachianesthésie pour césarienne : Comparaison de deux vitesses d'injection. Cah. Anesthesiol. 2004, 52 (5): 345-348

[20] Minif MA, Bougacha MA, Frikha N, Beladj N , Mebazaa MS ,Ben Ammar MS. Intérêt du préremplissage vasculaire lors de la césarienne programmée sous rachianesthésie. Ann $\mathrm{Fr}$ Anesth Réanim 25 (2006) S150-S153. doi:10. 1016/j.annfar.2006.07.045 https://www.emconsulte.com/article/52203/article/ obstetriquerachi-anesthesie.

[21] Bouchnak M, Belhadj N, Chaaoua T, Azaiez W, Hamdi M, Maghrebi H. Rachianesthesie pour césarienne : La vitesse d'injection a-t elle une influence sur l'incidence de l'hypotension? Ann Fr Anesth Réanim. 2006 ; 25 (1) : 17-19

[22] Shende D, Cooper GM, Bowden MI: The influence of intrathecalFentanyl on the characteristics of subarachnoid block for caesarean section. Anaesthesia 1998;53(7):70610. https://doi.org/10.1046/j.1365-2044.1998. 329-az0482.x

[23] Sertznig, C., Vial, F., Audibert, G., Mertes, P.M., El Adssi, H., \& Bouaziz, H. (2011). Enquête de pratique en région Lorraine sur la prévention et le traitement de l'hypotension au cours de la rachianesthésie pour césarienne programmée. Ann Fr Anesth Réanim. 30(9), 630-635. doi:10.1016/ j.annfar. 2011.03.022

[24] Triki Z ; Krid K, Kallel S, Amouri F, Sow A, Grab B, and al. Rachianesthesie pour cesarienne : Effets de l'adjonction Intrathecale de Midazolam aux Faibles doses de bupivacaine. Ann Fr Anesth Réanim (2006)25: S150-S153 doi:10.1016/j.annfar.2006.07.045 https://www.em-consulte.com/article/52203/ article/obstetrique-rachi-anesthesie.

[25] Van Steeberg.A, Joos S. Anesthésie péridurale, caudale et rachidienne In Anesthésieréanimation chirurgicale, 2ème édition; $\mathrm{K}$ Samii. Médecine -sciences Flammarion; p53749

[26] Gajanan Chavan, Aparna Chavan, Alok Ghosh. Effect of Intrathecal Fentanyl on subarachnoid block with $0.5 \%$ hyperbaric bupivacaine. IJHBR 2014; 2(4) : 67-76. www.ijhbr.com ISSN: 2319-7072

[27] Lu Q, Dong CS, Yu JM, Sun H, Sun P, Ma $\mathrm{X}$, Luo C. The dose response of sufentanil as an adjuvant to ropivacaine in cesarean section for relief from somato-visceral pain under epidural anesthesia in parturients with scarred uterus. Medicine (Baltimore). 2018;97(38):e12404. doi: 10.1097/ MD.000000000 0012404.

[28] Siddik-Sayyid SM, Nasr VG, Taha SK, Zbeide RA, Shehade JM, Al Alami AA, Mokadem FH, Abdallah FW, Baraka AS, Aouad MT. A randomized trial comparing colloid preload to coload during anesthesia for elective cesarean delivery. Anesth Analg 2009;109(4):1219-24

[29] Hunt CO, Naulty JS, Bader AM, Hauch MA, Vartikar JV, Datta S, Hertwig LM, Ostheimer GW. Perioperative analgesia with subarachnoid Fentanyl - bupivacaine for cesarean delivery. Anesthesiol 1989; 71: 53540

Citation: Ango Privat Desire, Kone Nabitou, Adje Tchimou Serge, Kouame Kouadio Antoine, Sai Servais Sontia, Diomande Sogbety Erick, Boua Narcisse. Comparative Study of 2 Doses of Sufentanyl (2.5 Mg versus $5 \mathrm{Mg}$ ) in the Rachianesthsia for Cesarean Section. ARC Journal of Anesthesiology. 2019; 4(1):17-22. DOI: dx.doi.org/10.20431/2455-9792.0401003.

Copyright: (C) 2019 Authors. This is an open-access article distributed under the terms of the Creative Commons Attribution License, which permits unrestricted use, distribution, and reproduction in any medium, provided the original author and source are credited. 